\title{
4
}

\section{Developing methods for recording surface artefacts in situ on nineteenth and twentieth century sites in Australia}

\author{
Samantha Bolton
}

\author{
Archaeology M405 \\ University of Western Australia \\ 35 Stirling Highway \\ Crawley WA 6009
}

\begin{abstract}
Surface artefacts are a common type of archaeological deposit in Australia. During field recording of ten sites along the Mundaring-Kalgoorlie historical settlement corridor, Western Australia, in 2004 and 2005, methods were developed to record in situ surface artefacts at sites from the late nineteenth and early twentieth centuries. The types of features and artefacts recorded included structural remains; large areas where individual features could not be distinguished; artefact scatters containing glass, ceramic and metal among other materials; bottle glass dumps; and individual artefacts. Detailed spatial data about the location of the archaeological material and surrounding topography were recorded using differential GPS. Using the archaeological and historical data, an analysis of when the sites were occupied, how they were used and by whom, was conducted. The research considers whether these methods are able to address the difficulties inherent in recording large, complicated surface historical sites.
\end{abstract}

Keywords: surface sites, recording methods, Mundaring, Kalgoorlie, Goldfields Water Supply Scheme, Bullabulling

\section{Introduction}

The majority of archaeological artefacts found in Australia are from surface scatters (Burke and Smith 2004: 202; Holdaway et al. 1998: 1). Despite this, most archaeological research continues to concentrate on excavated, and therefore collected, material, particularly in historical archaeology (Crook et al. 2002; Murray 2002: 11). Studies in historical archaeology that have recorded surface material in situ include the Central Australia Archaeology Project (Birmingham 1997) and Paterson's work in the south-western Lake Eyre Basin (Paterson 1999, 2003, 2005). Many studies of prehistoric sites are also of surface scatters and methods have been developed to record these sites. 
There has been much discussion about how much information can be recorded at surface sites, and some of the associated problems (e.g. see Lewarch and O'Brien 1981; papers in Sullivan 1998; Redman 1987; Wandsnider and Camilli 1992). As part of a study on prehistoric sites in Sturt National Park, western New South Wales, Holdaway et al. (1998: 3) identified four main difficulties applicable to recording surface sites. First, the lack of chronological control because of the absence of stratigraphy; second, the difficulty in determining site boundaries and features demarcated by a group of artefacts; third, identifying and interpreting artefacts in the field; and fourth, the problem of obtaining a representative sample from sites where there is uneven exposure or visibility. Because these problems are also relevant to historic sites they need to be taken into account when recording them.

Different research questions require different approaches, and this paper presents one way to record a large number of surface sites from the historic period. The aim was to record the archaeological information in situ, and to determine whether it was possible to obtain the minimum required information (as defined by the research questions) without collecting the archaeological material. A case study from late nineteenth and early twentieth century Western Australia is used to discuss the methods, and whether they can help overcome the problems identified by Holdaway et al. (1998) at sites representing the historic period.

\section{The archaeological project}

Archaeology in the School of Social and Cultural Studies, University of Western Australia and the National Trust (WA) were awarded an ARC Linkage Grant to conduct archaeological investigations of nineteeth and twentieth century society along the Mundaring-Kalgoorlie settlement corridor following the Goldfields Water Supply Scheme, and this research is part of that project. The National Trust (WA) manages many of the sites associated with the Goldfields Water Supply Scheme and is currently undertaking a major heritage project of the region, the Golden Pipeline Project, conducting interpretation and conservation of sites associated with the scheme. The region between Perth and Kalgoorlie is important in the development of Western Australia's European history, particularly in the search for pastoral land and gold. While there have been numerous historical and sociological studies of the area, usually focusing on Kalgoorlie, there has been very little archaeological work done in this region postEuropean settlement.

The aim of the Mundaring-Kalgoorlie Settlement Corridor archaeological project is to conduct archaeological investigations of nineteenth and twentieth century society between Mundaring, east of Perth, and Kalgoorlie, Western Australia, following the Goldfields Water Supply Scheme (Figure 1) to determine what kinds of settlements evolved along the migration route. The study period is from 18301914, as this area of Western Australia was settled by Europeans in 1830. 1914 serves as a convenient cutoff point, mainly due to technological changes in manufacturing methods around the time of the First World War.

The overall research questions relate to how the settlement sites that were occupied for various periods of time differed, and how those living and working along the corridor utilised the available resources at both temporary and permanent sites. This includes who was living there; the spatial organisation of the sites; how long they were occupied for; what material culture was used; and how this information relates to the historical record. Chronological and spatial information about the site from the archaeological data, and functional information about the artefactual material, help to answer these questions by identifying occupation and activity areas, and the period and nature of their occupation.

The study region is approximately $560 \mathrm{~km}$ long, and is within an arbitrary boundary of $15 \mathrm{~km}$ either side of the pipeline. Archaeological sites within this region were chosen for study based on several criteria. Sites chosen had archaeological material present from the study period of 1830-1914; were not heavily disturbed by later use; and were selected to cover a range of different site uses, including railway stations, town sites and water condensers. 


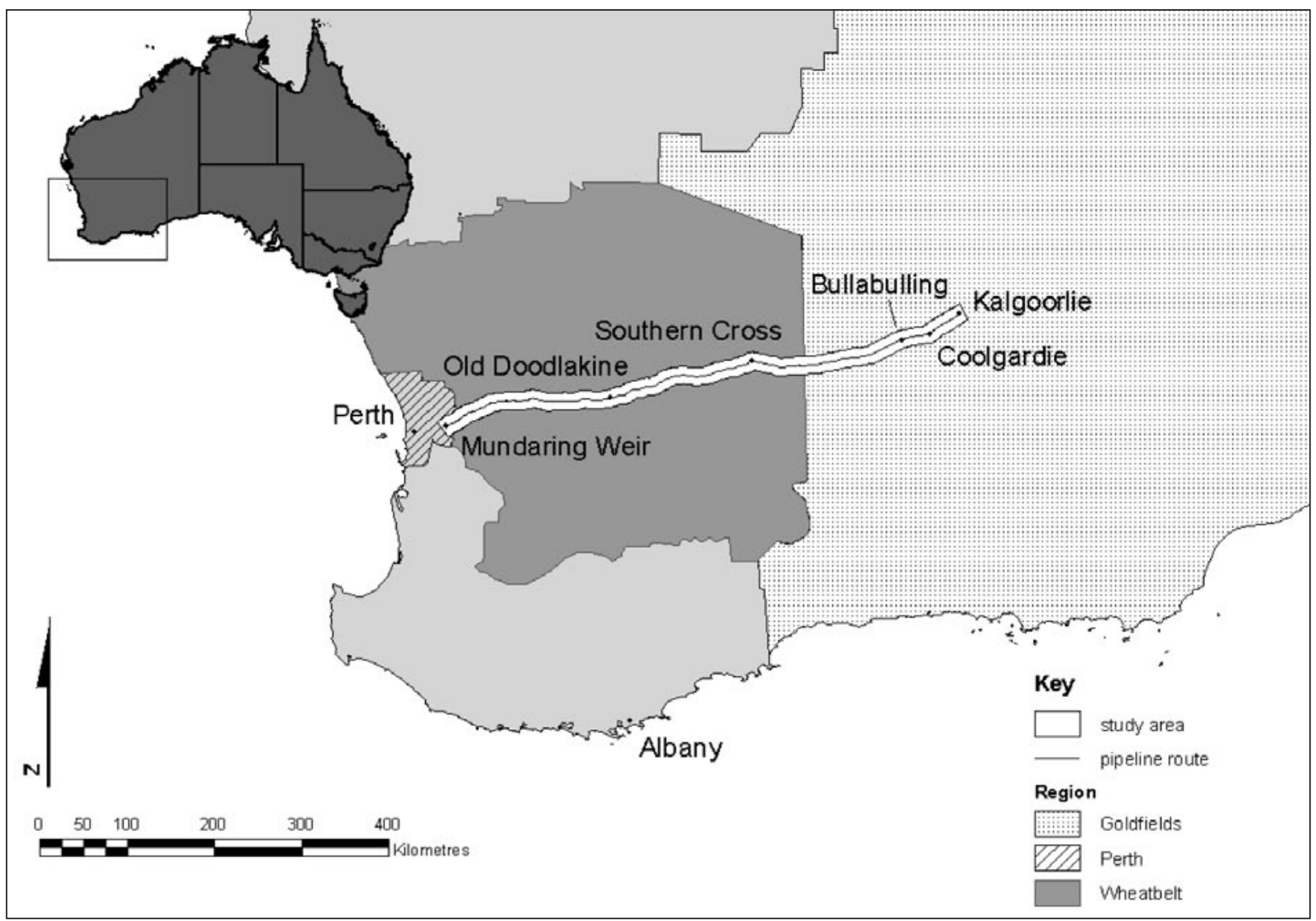

Figure 1. Location of study area including administrative regions and sites mentioned in text

The majority of the study area is within two modern administrative regions known as the Wheatbelt and the Goldfields (Figure 1). The Wheatbelt is an agricultural area, with low-moderate rainfall, and the sites in this region are usually either on agricultural land or have been classed as public reserves. East of Southern Cross, the Goldfields are in a semi-arid environment. Most of the sites are within national parks, although some are on leased or unallocated Crown Land. The two major land uses have significantly affected the preservation of sites and artefacts within each region.

Most sites in the Wheatbelt were destroyed by later occupation, and only one (Old Doodlakine) had enough undisturbed archaeological material to be included in the study. Sites in the Goldfields contained surface material and shovel test pits were excavated to confirm that there was little sub-surface archaeological material. The artefactual material across all of the sites included surface scatters of cans, glass, ceramics and metals, as well as isolated artefacts and artefacts common on late nineteenth and twentieth century sites, for example clay pipe fragments and charcoal.

\section{Methods}

The methods were designed to record the material in situ in a way that was both simple and accurate. Because the research questions included a comparison of different sites along the route, as many as possible needed to be recorded in the time available. Systematic sampling of each site was used to identify trends in spatial distribution of the archaeological material and characterise the assemblages, with minimal disturbance.

The methods for this project were adapted from those developed by Birmingham and Wilson for the Central Australia Archaeology Project (CAAP), during which material from a similar time period and 
in a similar environment was recorded (Birmingham 1997: 4-6). Surveys in 1995 and 1996 for the CAAP identified 100 sites comprising over 5000 features, which is comparable in scale to this project. The approach used by the CAAP were developed to record information from as many features 'as possible, with consistent data recording on each for systematic entry into a GIS [Geographic Information Systems] database' (Birmingham 1997: 4). To achieve this Birmingham and Wilson used survey and feature recording, which also formed the basis of data recording for this project.

For the sites recorded along the Mundaring-Kalgoorlie settlement corridor, site survey was conducted to determine the extent and the location of archaeological material. The survey methods varied, both between and within sites, according to topography and ground coverage. In order to determine the site boundary and the extent of the artefactual material within that boundary, transects, ranging from $5 \mathrm{~m}$ to $20 \mathrm{~m}$ according to visibility, were walked. Also, discrete areas, normally delineated by features such as the pipeline and railway line, were defined, and individual team members recorded all features within them. As well as the systematic survey, all sites were walked several times during the process of feature and GPS recording, which provided an extra check that all features were noted and recorded.

A site chosen for intensive study, as per the criteria outlined above, was divided into features which ranged from structures, scatters of artefacts, both discrete and disperse, to isolated artefacts. All features were designated a type (Table 1) and recorded, resulting in a qualitative and quantitative record of each based on previously established terminology conventions.

\begin{tabular}{|c|c|}
\hline Feature type & Definition \\
\hline general cover & $\begin{array}{l}\text { a spread of artefacts over a large area such that individual } \\
\text { depositional events cannot be discerned }\end{array}$ \\
\hline scatter & $\begin{array}{l}\text { a discrete area of artefacts that consists of several different material } \\
\text { types, for example glass, ceramics and metal }\end{array}$ \\
\hline cluster & $\begin{array}{l}\text { a discrete area of artefacts that contains one material type and is } \\
\text { the result of a single event, e.g. a bottle breaking }\end{array}$ \\
\hline single artefact & single artefact \\
\hline arbitrary point & arbitrary point \\
\hline structure - regular & usually a four sided structure, such as a building \\
\hline structure - non-regular & any other structure \\
\hline fill & a depression containing artefacts, opposite to a heap \\
\hline heap & a raised area of artefacts, opposite to a fill \\
\hline other & a feature type not covered by other definitions \\
\hline
\end{tabular}

Table 1. Feature types and definitions

The feature types provide a means of characterising the distribution of artefacts, interpreting how the site was used, and how the archaeological record was formed. For example, a scatter, which is the most common feature type, is often formed as a result of several events over a period of time, whereas a cluster is the result of a single event. Assigning a type to a given feature does not mean that different types cannot be compared. The comparison is of artefact distribution, date of manufacture and function, which are independent of the feature type.

The edge of a feature was defined as the point where the concentration of artefacts effectively drops to zero. This was not always easy to determine as it was sometimes unclear whether the spread of artefacts related to the feature being recorded or an adjacent one. It was necessary to make assumptions, and sometimes draw arbitrary boundaries between two adjacent features. By defining the extent of the 
feature and classifying it as a particular type the recorder was forced to think about the feature and what it actually constituted.

As most of the sites were in a semi-arid environment, surface visibility was generally high $(>90 \%$ for individual features). However, it is inevitable that artefacts were missed, particularly very small items such as pins, sew-on hooks and eyelets, and items that are hard to see. For example, throughout the study region, there was a very low number of clay pipe fragments (less than ten over all of the sites recorded) and one of the reasons for this may be due to visibility. Clay pipes are commonly found on nineteenth and early twentieth century sites in Australia (Lawrence 2006: 368; Courtney and McNiven 1998: 44), and it was expected that there would be a higher number on these sites. Although there was high surface visibility, there was a bias towards larger artefacts and those that are more brightly coloured, such as glass and ceramics.

In order to determine artefact distribution and activity areas across the site, the artefacts were counted usually according to raw material (e.g. glass colour, ceramic type), although some artefacts were counted according to type (e.g. can, insulator, copper grommet). Zones of different artefact concentration were identified within a feature and the artefacts were counted within each zone. If a feature had greater than 100 artefacts then a representative area, usually a $1 \mathrm{~m} \times 1 \mathrm{~m}$ square, was chosen from each concentration zone as a sample for the artefact count. From a sketch plan of the feature, including the different zones, the surface area was determined and the total artefact count was calculated for that feature based on the sample squares.

The artefact classifications of raw material or artefact type were based on common objects found on similar sites (e.g. Birmingham 1997; Paterson 1999) and from observations made during earlier visits. Raw material is one of the primary levels of information about an artefact that can be recorded, and does not require any level of interpretation (see Crook et al. 2002; Brooks 2005 for a discussion of the issues related to artefact catalogues and interpretation of artefacts). Broad inferences can be made about the original intended function of an artefact based on its raw material. For example, curved coloured glass is associated with vessels, as opposed to flat window glass. Dark olive (black) and olive glass are associated with alcohol bottles, amber is associated with beer, medicines or chemicals, and tinted glass is associated with food storage bottles. Although these classifications are not absolute, it is possible to get an overview of the distribution of artefacts across a site based on these counts. Further refinement of artefact use and activity areas was done by more detailed recording of selected artefacts as described below.

Unlike glass or ceramic which could be easily differentiated based on other aspects of their material type such as colour or ware, metals, in particular iron, needed to be separated by artefact type in order obtain a count that could be used for further analysis. These types included cans, nails, gun cartridges, scrap iron and copper grommets. Again, these were broad categories chosen in order to gain an overview of the type of material present. Artefacts such as telegraph insulators and electrodes were also counted according to type as it was an easy way to distinguish them from other materials. By using these categories for the counts, it was possible to obtain a detailed map of the distribution of artefacts across the site, in order to help answer the research questions.

Artefacts with identifying features that allowed them to be dated were recorded in further detail for a later functional analysis. The artefacts included any items with inscriptions, cans, buttons, nails, unusual artefacts or artefacts that could not be easily identified on site. The attributes recorded about these artefacts were material (e.g. glass colour, metal type); form (bottle, jar, can etc.); technology (hand or machine made); shape; modifications; inscriptions; dimensions; and minimum item count. A set of established attribute codes was used to record these attributes. When there were no codes for a given artefact, the recorder gave a detailed description with either a diagram and/or a photograph.

To identify recycled and reused artefacts (e.g. see Stuart 1993; Busch 1987 for discussions of bottle reuse) modifications to the artefact were noted. However, unless there are any obvious modifications, it is often almost impossible to determine whether or not an artefact has been reused, and if so, what for. Therefore, the assumption was made that each artefact was used according to its primary intended function, and it was that function that was recorded. 
The attributes recorded provided information to answer questions about what artefacts were used, where and when they were made, and how, if at all, they were adapted for other uses. The codes enabled this information to be recorded in the field in a relatively fast and systematic way, so the information recorded by different people was directly comparable, therefore addressing the problem of identifying and interpreting artefacts. Additionally, diagnostic information, such as inscriptions, technology, form and colour, provided a terminus ante quem for occupation of the site and a given area, thereby giving a level of chronological control.

The survey component consisted of recording the location of each feature using a differential global positioning system (dGPS). The GPS location of each feature was combined with the sketch plan of the feature using GIS software (ArcGIS) to create a site plan. The artefact count was then linked to the individual feature points on the site plan in order to give a visual representation of artefact distribution (e.g. Figure 2). This information is used to provide overall maps of the site and its boundary, different activity areas, and how occupation of the site varied over time.

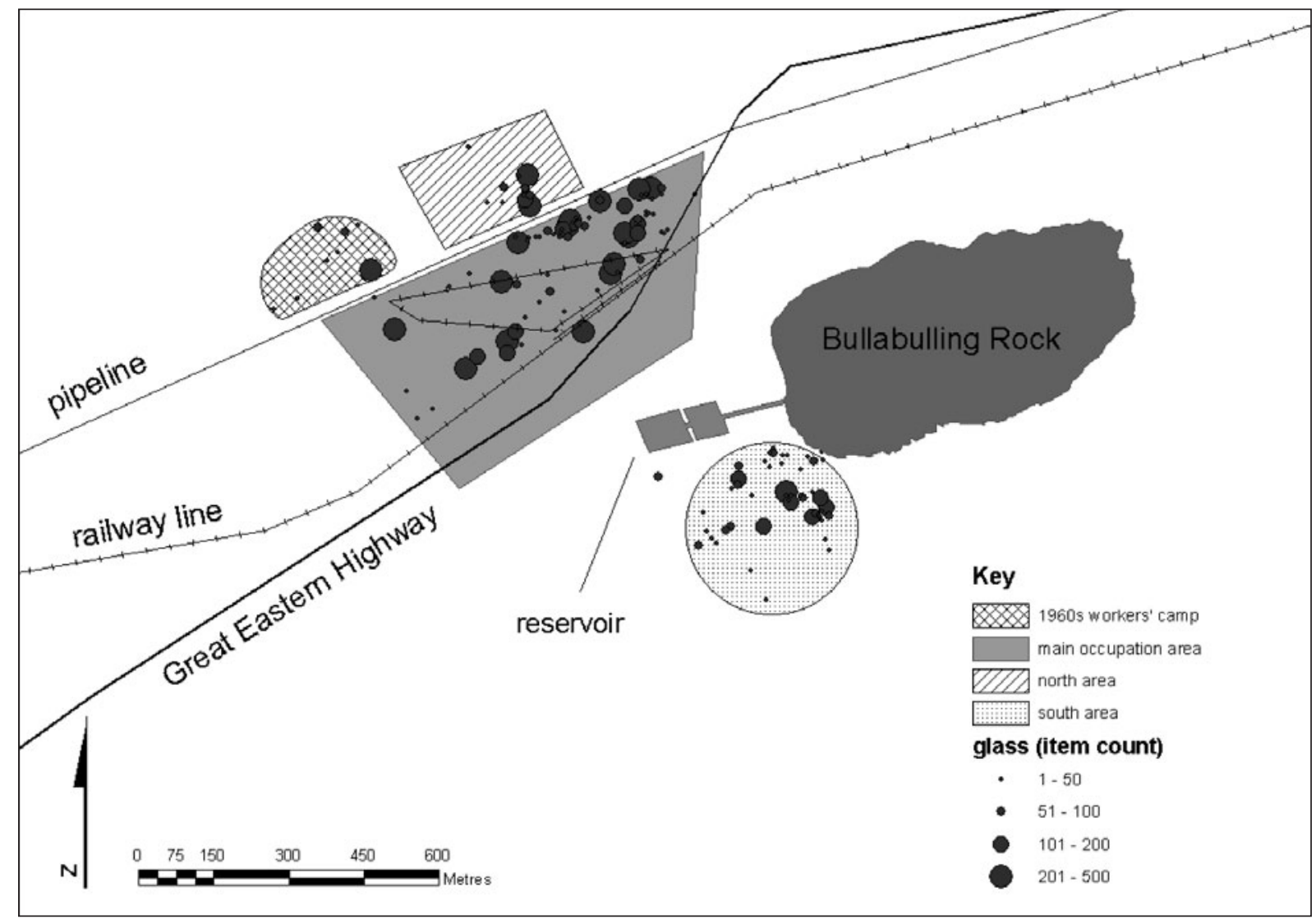

Figure 2. Site plan of Bullabulling showing distribution of glass

\section{Case study}

A case study of one of the sites in the study, Bullabulling, illustrates how these methods can overcome the problems associated with surface site recording to produce information with chronological control and answer the research questions. Bullabulling was a town site and railway station established in 1893 as a watering point, for trains and people ( $\mathrm{RICH} 2001$ : 7) (Figure 1). The site is located at the base of a $15 \mathrm{~m}$ high granite outcrop and was built as a rock catchment, which is a wall of upright granite slabs, 
approximately $0.5 \mathrm{~m}$ high, built around the base of a granite outcrop designed to catch the water flowing off the rock and channel it into a reservoir. Its population reached a maximum of 54 in 1903 (RICH 2001: 9) and, following the closure of the railway in the 1960s, the population dramatically declined, to the current level of two.

Four major zones of occupation were identified based on the archaeological material (Figure 2, Figure 3). To the north and the south were two areas containing material almost exclusively produced before 1910, suggesting that these areas were abandoned by this date. The artefacts in the northern area included hole-in-cap cans, common before 1910 (Rock 1984), which were recorded as individual objects. In the southern area, among other artefacts, there was glass predominantly from the 1890s (see discussion below, Figure 4) and a large number of torpedo, or egg-shaped, bottles, common in the nineteenth century (Jones and Sullivan 1989: 72). To the northwest of the site is a 1960s workers' camp (Rosa Minozzi pers. comm. 2004; RICH 2001:9) which was not included in the study as it was outside the study period.

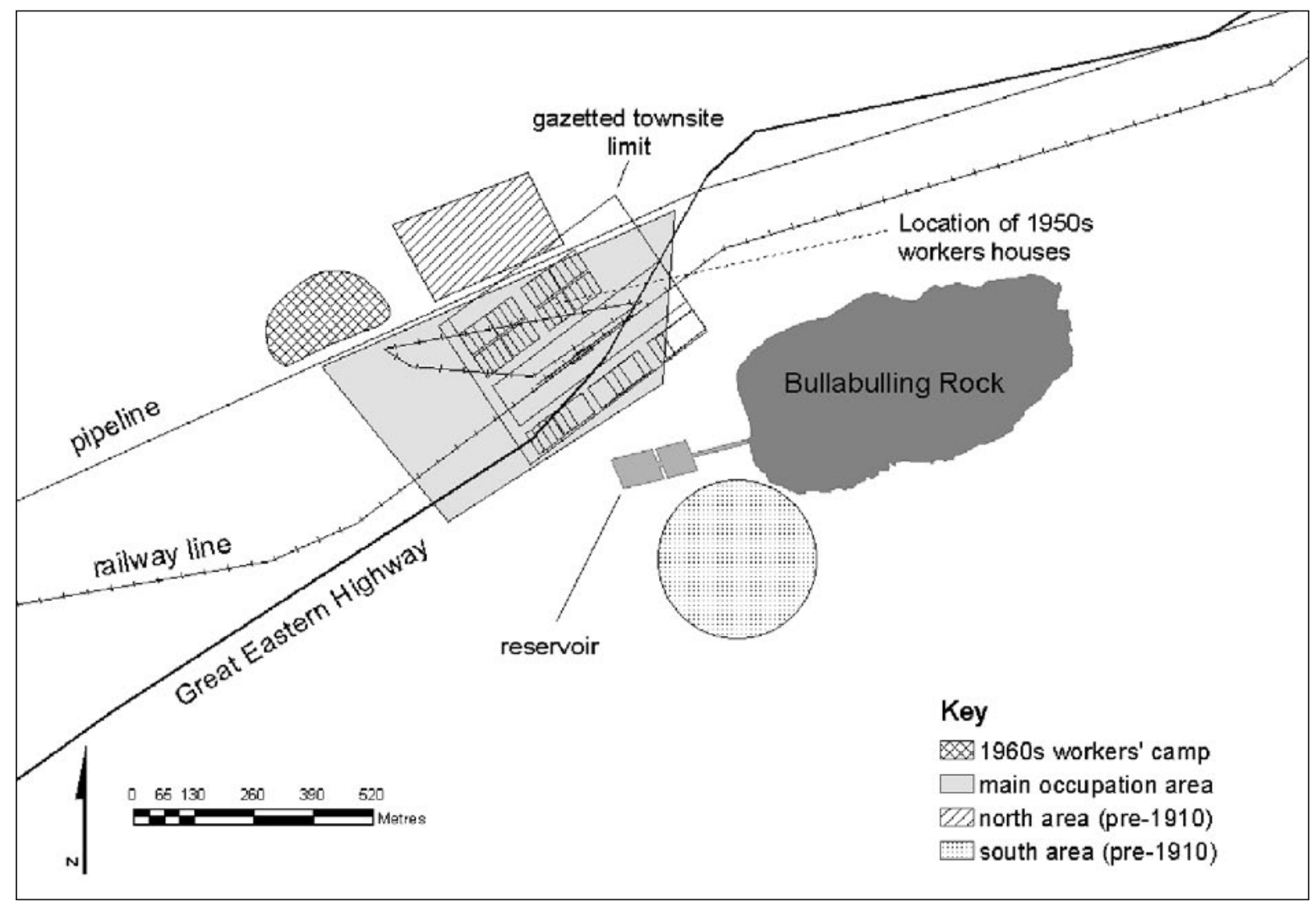

Figure 3. Site plan of Bullabulling showing areas of archaeological deposits

From the artefact counts and the location of the features, the distribution of artefact types can be seen (Figure 2). Figure 4 is a graph of the distribution of glass according to colour and indicates that the colours commonly associated with older bottles (e.g. dark olive and amethyst) are more common in the northern and southern areas, and those associated with more modern bottles (e.g. amber, which at this site came only from items that were produced after 1920) are most common in the central area. Using glass colour to date the manufacture of bottles is not definitive, however it can serve as a useful guide to overall trends (Jones and Sullivan, 1989:12; also see Boow, 1991; Lockhart, 2006; Bolton, 2005; Burke and Smith, 2004 for some guides to the dating of glass based on colour). 


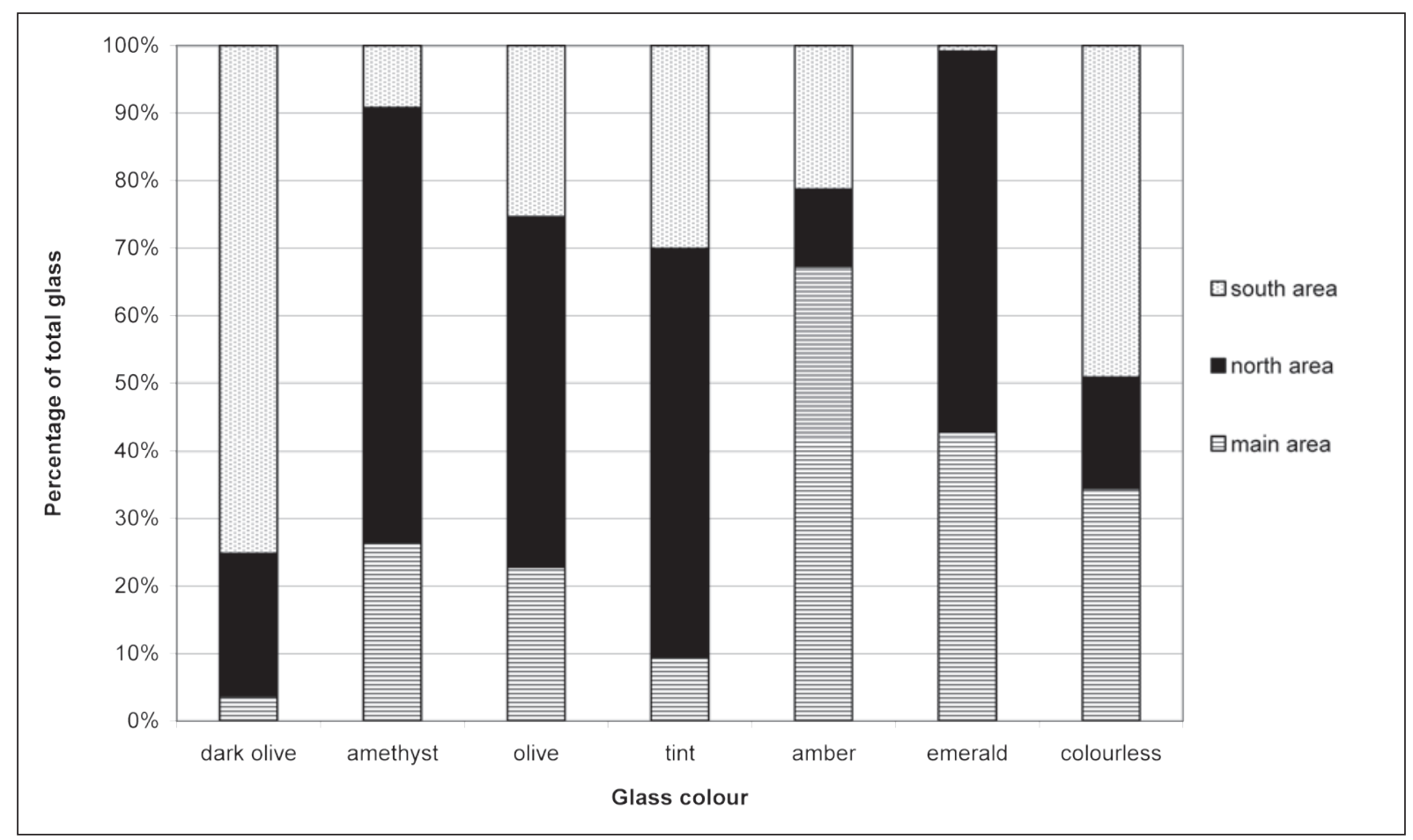

Figure 4. Distribution of glass at Bullabulling according to colour

From the amount and date range of all of the artefactual material, recorded using the artefact counts and individual object recording, and the location of the structures, it can demonstrated that the centre, where the gazetted townsite and railway station were (RICH 2001: 14), was the main focus of occupation. The artefacts here included material ranging in production from the late nineteenth century until the 1960s, and, as an example, Figure 2 shows that there is more glass in this central area.

Based on the distribution of archaeological material, the following interpretation can be made. Initial occupation occurred in the southern area, when the rock catchment was built. The focus then moved to the main area in the centre, around the railway station. At first this occupation included the area to north, however once the pipeline was built the area was cut-off and abandoned. Unlike other sites, there was no evidence for any ladders over the pipeline, so it was probably too difficult to constantly climb over.

At Bullabulling the archaeological material was used to determine different zones of occupation. Without stratified material it can be difficult to determine change over time, however, the combination of knowing when certain elements were built and the distribution of all artefacts from a given time period can be used to answer questions about changes in the site's use over time.

\section{Discussion}

The first problem raised by Holdaway et al. (1998) is the lack of stratigraphy on surface sites, and therefore chronological control. Historical records and technological changes in the manufacture of artefacts allow sites to be dated, and this inevitably makes it possible to date historical sites with a finer resolution than prehistoric sites. However, historical records for a given site do not always exist and there may be a time lag between the manufacturing date and the use of an artefact (Adams 2003). Also, artefacts were often recycled and re-used. Despite these problems, based on the distribution of archaeological material at Bullabulling, it was possible to identify different zones of occupation. Allowing for time lag, the zones were based on the clear demarcation of artefacts from different time periods. 
The second problem identified by Holdaway et al. that activity areas are difficult to identify because feature boundaries are not clear is dealt with by using arbitrary boundaries. Features often do not have clear boundaries, and at some point a decision has to be made about their extent. By recording different zones of artefact concentration and looking at the site as a whole, activity areas can be identified and interpretations made about the use of the site.

The problem of identifying and interpreting an artefact's use for applies to both historic and prehistoric artefacts. When recording artefacts in the field, less information is often recorded about them, for example it is difficult to weigh artefacts in the field, and the artefacts cannot be checked. Whether it is necessary to record that information depends on what the research questions are. In this project in situ recording was sufficient as the questions related to the spatial organisation of the site, what was being used, when and how, and by whom. By identifying the artefacts that have diagnostic information and recording only those, and by standardizing the recording as much as possible, time is spent in the field recording the information required to answer the research questions.

The third problem about exposure and visibility of features and artefacts varies between and within sites. This was dealt with by conducting a systematic survey of the site, followed by feature recording and the GPS survey, ensuring that the location and composition of all exposed features were recorded.

In addition to the problems identified by Holdaway et al. other factors affect surface sites. These include a greater potential for disturbance by environmental, animal and human factors, and when recording surface sites in situ, there is a bias towards larger artefacts, such that small personal items, including pins, eyelets as well as clay pipe fragments, may not be seen and recorded.

Regarding the greater potential for disturbance by environmental, animal and human factors, surface artefacts from the historical archaeological period are highly visible. They are prone to be blown by the wind, washed away during heavy rain, kicked about by passing animals and picked up, moved, and taken away by artefact collectors and the curious. Numerous bottle dumps have been identified at the sites recorded, and because they are very visible, without fail, all have been raided by collectors. However, features recorded at several sites have clear spatial patterns that indicate they have not been significantly disturbed.

There will be a bias towards larger artefacts such that small items may not be recorded. Nevertheless, small artefacts, including buttons, eyelets and sew-on hooks, have been found in this project and recorded at a number of features, demonstrating they are not being missed altogether. By studying the distribution of artefacts using the GIS, and incorporating other factors such as topography and ground coverage, it may be possible to predict where the small artefacts are likely to be located.

\section{Conclusion}

Chronological controls provided by the presence of material of a known period of production allow the interpretation of site functions over time. Unlike prehistoric sites, historical archaeological sites usually feature some datable material. Changes in manufacturing technology, the use of makers' marks, and the introduction of new items and new materials, enable the production of many individual artefacts to be dated. Using the archaeological and historical records it is possible not only to provide a terminus ante quem for dating the occupation of a site as a whole, but different components of the site.

The artefacts are also used to identify different activity areas such as a workshop of domestic area. Not only can an interpretation be made about what areas of a site were used at different times, it is also possible to determine how, if at all, these functions changed over time. By studying the distribution of artefacts from earlier periods of occupation as compared to those from later periods, it may be possible to determine how the site was used over time and the rate of change.

The methods described here are one way of recording archaeological data from historic period sites in situ. Further testing and development will ultimately determine whether they are successful. 
Surface artefacts are a major component of the archaeological record in Australia for sites occupied in all time periods. There are numerous difficulties inherent in recording surface artefacts, mostly relating to dating and preservation of sites. Yet they are important sources of archaeological information, and it is necessary to continue to develop and refine methods to record them, such that questions about a site can be answered.

\section{Acknowledgements}

This project is funded by an ARC Linkage Grant awarded to Alistair Paterson, Archaeology, UWA and the National Trust (WA). Thanks to Alistair Paterson and Jane Balme, Archaeology, UWA; Anne Brake, Kelly Rippingale, Diana Frylinck and the National Trust (WA); Department of Archaeology and Natural History, ANU; Mike Stewart, Department of Spatial Sciences, Curtin University; Cameron Waters, GlobalPOS; Geoff Glazier, OmniSTAR; Barry Hooper, DEC (previously CALM); Andrew Wilson, University of Sydney; Laurie and Rosa Minozzi, Bullabulling Tavern; Lara Bosi, Kelly Fleming, Shaun Mackey, Daniel Monks, Stafford Smith, Norbert Svatos and Vicky Winton. Jane Balme, Shaun Mackey, Peter Davies and two anonymous reviewers provided invaluable comments on earlier versions of this paper. All errors and omissions are my own. 


\section{References}

Adams, W. H. 2003. Dating historical sites: the importance of understanding time lag in the acquisition, curation, use, and disposal of artifacts. Historical Archaeology 37(2):38-64.

Birmingham, J. 1997. Fieldwork in contact archaeology, Central Australia. In C. Petrie and S. Bolton (eds), In the Field, pp 1-12. Sydney: Sydney University Archaeological Methods Series.

Bolton, S. 2005. Purple Haze: evidence for a later date for solarized amethyst glass. Australian Archaeology 60:51-52.

Boow, J. 1991. Early Australian Commercial Glass: Manufacturing Processes. Sydney: Heritage Council of NSW.

Brooks, A. 2005. An Archaeological Guide to British Ceramics in Australia, 1788-1901. The Australasian Society for Historical Archaeology and The La Trobe University Archaeological Program.

Burke, H. and C. Smith. 2004. The Archaeologist's Field Handbook. Australia: Allen and Unwin.

Busch, J. 1987. Second time round: A look at bottle reuse. Historical Archaeology 21(1):67-80.

Courtney, K. and I. J. McNiven. 1998. Clay tobacco pipes from Aboriginal middens on Fraser Island, Queensland. Australian Archaeology 47:44-53.

Crook, P., S. Lawrence and M. Gibbs. 2002. The role of artefact catalogues in Australian historical archaeology. Australasian Historical Archaeology 20:26-38.

Holdaway, S., D. C. Witter, P. Fanning, R. Musgrave, G. Cochrane, T. Doelman, S. Greenwood, D. Pigdon and J. Reeves. 1998. New approaches to open site spatial archaeology in Sturt National Park, New South Wales, Australia. Archaeology in Oceania 33:1-19.

Jones, O. and C. Sullivan. 1989. The Parks Canada Glass Glossary for the Description of Containers, Tableware, Closures, and Flat Glass. Quebec, Canada: National Historic Parks and Sites, Canadian Parks Service, Environment Canada.

Lawrence, S. 2006. Artifacts of the modern world. In J. Balme and A. Paterson (eds), Archaeology in Practice: A student guide to archaeological analyses, pp 362-388. Malden, USA: Blackwell Publishing.

Lewarch, D. E. and M. J. O'Brien. 1981. The expanding role of surface assemblages in archaeological research. In M. B. Schiffer (ed), Advances in Archaeological Method and Theory, pp 297-342. New York: Academic Press.

Lockhart, B. 2006. The color purple: Dating solarized amethyst glass containers. Historical Archaeology. 40(2):25-56

Murray, T. 2002. But that was long ago: Theory in Australian historical archaeology 2002. Australasian Historical Archaeology 20:8-14.

Paterson, A. G. 1999. Confronting the sources: The archaeology of culture-contact in the South-Western Lake Eyre Basin, Central Australia. Unpublished PhD thesis, Dept. of Prehistoric and Historical Archaeology, Faculty of Arts, University of Sydney, Sydney, NSW.

Paterson, A. G. 2003. The texture of agency: An example of culture-contact in central Australia. Archaeology in Oceania 38:52-65.

Paterson, A. G. 2005. Early pastoral landscapes and culture contact in Central Australia. Historical Archaeology 39(3):28-48.

Redman, C. L. 1987 Surface collection, sampling, and research design: A retrospective. American Antiquity 52(2):249-265.

Research Institute for Cultural Heritage (RICH). 2001. Conservation Plan for Bullabulling Township and Railway Catchment - DRAFT. Unpublished Draft Report prepared for National Trust of Australia (WA), Perth.

Rock, J. T. 1984. Cans in the countryside. Historical Archaeology 18(2):97-111.

Stuart, I. 1993. Bottles for jam? An example of recycling from a post-contact archaeological site. Australian Archaeology 36:17-21.

Sullivan, A. P., III (ed). 1998. Surface archaeology. Albuquerque, New Mexico: University of New Mexico Press.

Wandsnider, L. and E. L. Camilli. 1992. The character of surface archaeological deposits and its influence on survey accuracy. Journal of Field Archaeology 19(2):169-188. 